\title{
Chromoendoscopy with red phenol in the diagnosis of Helicobacter pylori infection
}

\author{
Héctor Rubén Hernández-Garcés, Víctor V. Castellanos-González¹, Licet González-Fabián², \\ Mirtha Infante-Velázquez ${ }^{3}$, Kevin Peña ${ }^{1}$ and Yudit Andrain-Sierra ${ }^{1}$ \\ ${ }^{1}$ Department of Digestive Endoscopy, and ${ }^{2}$ Department of Pathology. Institute of Gastroenterology. Havana, Cuba. \\ ${ }^{3}$ Department of Gastroenterology. Hospital "Luís Díaz Soto". Havana, Cuba.
}

\begin{abstract}
An analytic study to validate a diagnostic test was carried out at the Institute of Gastroenterology in Havana, Cuba in adult patients of both sexes in whom chromoendoscopy was carried out with red phenol at $0.1 \%$ over the gastric mucosa for the detection of Helicobacter pylori infection between November 2008 and December 2010. The staining with red phenol at $0.1 \%$ is included in the invasive tests for the diagnosis of Helicobacter pylori infection and of the reactive techniques. The sensibility of red phenol dye in the diagnosis of Helicobacter pylori infection in the patients studied was of $72.6 \%$ with a confidence interval (C.I.) of 95\% (64.9 to $79.2 \%)$ and a specificity of $75.5 \%$ C.I. $95 \%$ (61.9 to $85.4 \%)$. The positive predictive value was of $89.8 \%$ C.I. $95 \%$ (83.1 to $94.1 \%$ ) and the negative predictive value of $48.1 \%$ C.I. $95 \%$ (37.3 to $59.0 \%)$. The proportion of false positives was of $24.5 \%$ C.I. $95 \%$ (14.6 to $38.1 \%$ ) and the proportion of false negatives was of $27.4 \%$ C.I. 95\% (20.8 to $35.1 \%)$. The diagnostic accuracy of the dye on the patients studied was $73.3 \%$ C.I. $95 \%$ (66.7 to $79.0 \%$ ). The diagnostic odds ratio was 8.17 C.I. $95 \%$ (3.88 to 17.23), the J Youden ratio of 0.5 and the Kappa coefficient of 0.40 C.I. $95 \%$ (0.27 to 0.54). The staining dye with red phenol at $0.1 \%$ resulted in a useful method in the diagnosis of Helicobacter pylori infection in the gastric mucosa, it can be applied in our environment and has multiple advantages (topographic localization, avoids contamination and fast and immediate reading).
\end{abstract}

Key words: Red phenol. Chromoendoscopy. Helicobacter pylori.

Hernández-Garcés HR, Castellanos-González VV, GonzálezFabián L, Infante-Velázquez M, Peña K, Andrain-Sierra Y. Chromoendoscopy with red phenol in the diagnosis of Helicobacter pylori infection.Rev Esp Enferm Dig 2012; 104: 4-9.

Received: 15-05-11.

Accepted: 14-07-11.

Correspondence: Héctor R. Hernández-Garcés. Havana, Cuba. e-mail: hhgarces@infomed.sld.cu

\section{INTRODUCTION}

For the diagnosis of Helicobacter pylori (H. pylori) infection, we dispose of invasive tests like histology, cultures, molecular tests and rapid urease test which are dependent on the taking of biopsies from the gastric mucosa through an upper digestive endoscopy and of none invasive tests which do not require upper endoscopy like serology, urea breath test or the detection of stool antigens (1-3).

The rapid urease test is a simple, fast and cost-effective method in the detection of $H$. pylori. It is based on the urease enzyme's properties which contains the bacteria in high dosages and allows the urea to be metabolized and transformed into ammonium (3-5).

The staining of the gastrointestinal tract has received little attention from western investigators even though its widespread use in other parts of the world. However, the interest for this technique has grown in the last years thanks to it being simple, cheap, and fast and practically has no adverse effects. Also the application of new techniques of chromoendoscopy in the diagnosis and follow up of a variety of pathologies that increase its utility in the routine endoscopic practice (6-8).

A promising clinical utility of red phenol is for the endoscopic detection of $H$. pylori infection in the stomach, at least as a complementary technique to the ones that already exist. The bacterial urease produces hydrolysis of urea to ammoniac and carbon dioxide which would cause the increase in the $\mathrm{pH}$ and the red staining of the infected zones. Red phenol turns from yellow to red in a basic $\mathrm{pH}$ in the infected zones.

Because of its reactive and non-absorptive characteristic, it is rapidly eliminated from the organism through the digestive system, without a report of toxicity $(9,10)$.

Presently, it is very important to validate methods, processes, etc., which allow higher confidence in results and that they show the aptitude for the use that they are destined to. All this motivated us to carry out the following investigation, with the objective to know the value of chromoendoscopy with 
red phenol at $0.1 \%$ combined with the rapid urease test in the diagnosis of $H$. pylori infection of the gastric mucosa.

\section{MATERIAL AND METHOD}

An analytic study to validate a diagnostic test was carried out on all patients older than 18 years of both sexes who came to the endoscopy department at the Institute of Gastroenterology (I.G.E.) in Havana, Cuba, with an indication for upper digestive endoscopy for different reasons. To these, the chromoendoscopy technique with red phenol at $0.1 \%$ over gastric mucosa for the detection of Helicobacter pylori infection was applied in a period between November 2008 and December 2010.

The sample was constituted by 195 patients with a positive proportion estimated at 80 , maximum accepted error of 0.08 and confidence interval of $95 \%$.

All patients selected for this study fulfilled the following criteria.

\section{Inclusion criteria}

- Patients older than 18 years.

- Patients of both sexes who came to the department of digestive endoscopy at the I.G.E. with an indication for a diagnostic upper digestive endoscopy.

- Patients who with conformity and voluntarily participate in the study.

\section{Exclusion criteria}

- Patients below 18 years.

- Patients who are allergic to red phenol.

- Patients who do not wish to participate in the study.

- Patients who have received antisecretory treatment up to 6 months before the endoscopic study.

- Patients who have received treatment to eradicate $H$. pylori infection up to 6 months before the test.

- Patients with gastric surgery.

\section{Exit criteria}

- Insufficient sample of material from gastric biopsy or not useful for histological diagnosis.

\section{Ethical considerations}

The study is justified from an ethical point of view in accordance with the principles of the Helsinki declaration and without conflict of interest. Prior to the endoscopic study, a written consent was solicited from the patient to carry out the investigation, and the approval from the sci-

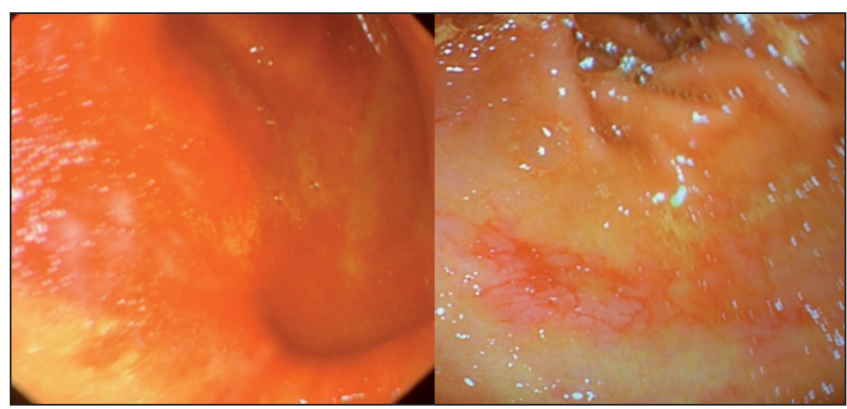

Fig. 1. Chromoendoscopic technique with red phenol at $0.1 \%$ over the gastric mucosa. Zone with red stain (positive staining) and zones with persisting yellow color (negative staining)

entific counsel of the institution was obtained, without conflict of interest.

\section{Procedure}

Upper digestive endoscopy was carried out on all patients by the same endoscopist, utilizing a GIF Olympus EVIS LUCERA 260 with frontal vision. Once the endoscopic diagnosis had been made, it was then proceeded to make the chromoendoscopic staining, using a spray type catheter (Olympus PW 5L-1) instilling $20 \mathrm{ml}$ of red phenol at $0.1 \%$ over the mucosa of the gastric cavity in a homogeneous way, a minute was waited to visualize the reaction of the mucosa to the application of the dye. Subsequently, a sample of gastric mucosa was taken using a standard biopsy forceps (Olympus FB-25K-1) through the instrumentation channel from zones where there was reaction to the dye, red stain (positive), for histological study (gold standard), with the objective of identifying the presence or not of $H$. pylori. On patients where there wasn't a reactive staining of the dye, yellow color (negative staining), a biopsy sample of gastric mucosa from zones which are more frequently colonized by $\mathrm{H}$. pylori (incisura angularis, prepyloric region and body), were taken for histological study with the objective of detecting or not the presence of $H$. pylori infection (Fig. 1). The samples were placed in a bottle with formol, which was labeled with the patient's data, date and type of sample; afterward, it was sent to the pathology laboratory for its histological study using hematoxilin-eosin and Giemsa without previous knowledge by the pathologist of the chromoendoscopic study.

The variables that were measured in our investigation were:

\section{Variables}

Age: It was considered according to completed years:

- From 18 to 30 years.

- From 31 to 40 years.

- From 41 to 50 years.

- From 51 to 60 years.

- Older than 60 years. 


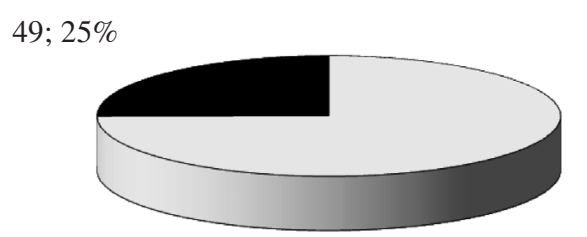

$146 ; 75 \%$

$\square$ H. pylori positive $\square$ H. pylori negative

Source: database

Fig. 2. Distribution of patients, positive or negative to $H$. pylori infection according to histological study. I.G.E. 2010.

Sex: According to biological sex.

- Femenine.

- Masculine.

\section{Chromoendoscopic diagnosis}

The following dye criteria were established for the reactive under validation (red phenol at $0.1 \%$ ):

- Positive reactive staining: mucosa that takes a red color when put in contact with the dye.

- Negative reactive staining: mucosa takes a yellow color when put in contact with the dye.

\section{Histological diagnosis}

The histological diagnosis of the gastric mucosa was only limited to the morphologic description on the presence or not of $H$. pylori infection according to the Sydney System of one of the measurable variables (density of $H$. pylori infection).

The chromoendoscopic and histological diagnosis were related.

\section{STATISTICAL ANALYSIS}

An automated database was created using Excel 2007. Sex and age were analyzed in a general and independent way shown in totals and percentages. The evaluating indicators of a diagnostic test were determined comparing the test (dye with red phenol) with the gold standard (histological diagnosis). The following indicators were determined: sensitivity, specificity, positive predictive value, negative predictive value, proportion of false negatives, exactness in diagnosis, diagnostic odds ratio, J Youden ratio, probability quotient or verisimilitude ratio, pre-test probability.

The concordance between tests (red phenol and histology) was evaluated with the Kappa coefficient, with the

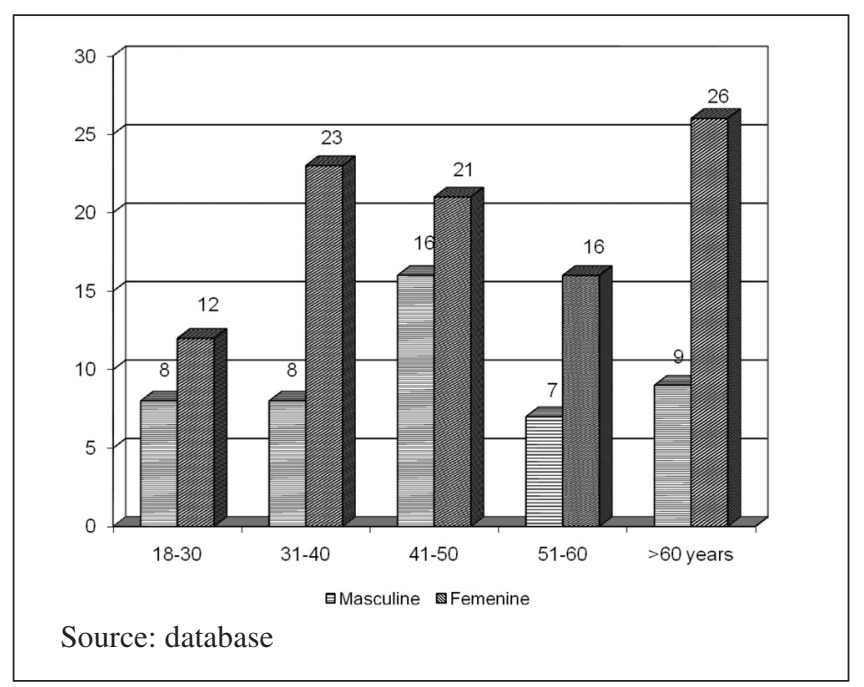

Fig. 3. Distribution of patients positive to $H$. pylori through histological study according to groups of ages and sex. I.G.E. 2010.

interpretation varying from -1 to 1 . Data was processed using a Pentium 4 computer and Epinfo 6.0.

\section{RESULTS}

As seen in figure 2 of the total patients under study, 146 patients (75.0\%), had the presence of $H$. pylori infection demonstrated by histological study. When observing the distribution of patients with positive $H$. pylori confirmed by histology according to groups of age and sex (Fig. 3), we could observe that the majority of cases were in the group of over 60 years for females and 41 to 50 in males $(26.7 \%)$.

Table I shows the statistical analysis from the relation between the chromoendoscopic diagnosis with red phenol at $0.1 \%$ and the histological diagnosis. Of 118 patients with a positive endoscopic staining, 106 had the presence of $H$. pylori infection through histological study. Of 77 patients with a negative endoscopic staining, the histological diagnosis was negative for $H$. pylori infection in 37 patients. According to these results, the sensibility of red phenol dye in the diagnosis of $H$. pylori in the gastric mucosa in patients studied was of $72.6 \%$ C.I. $95 \%$ (64.9 to $79.2 \%$ ) and the specificity of $75.5 \%$ C.I. $95 \%$ (64.9 to $79.2 \%$ ) and the specificity of $75.5 \%$. C.I. $95 \%$ (61.9 to $85.4 \%$ ).

The positive predictive value of the test was of $89.8 \%$ C.I. $95 \%$ (83.1 to $94.1 \%$ ) and the negative predictive value of $48.1 \%$ C.I. $95 \%$ (37.3 to $59.0 \%$ ). The proportion of false positive was $24.5 \%$ C.I. $95 \%$ (14.6 to $38.1 \%$ ) and the proportion of false negative of $27.4 \%$ C.I. $95 \%$ (20.8 to $35.1 \%$ ). The exactitude in diagnosis of red phenol dye in the patients studied was of $73.3 \%$ C.I. $95 \%$ (66.7 to $79.0 \%$ ).

The diagnostic odds ratio that has the advantage of gathering with a single indicator the exactitude of the test was 
Table I. Relation between the chromoendoscopic diagnosis with red phenol at $0.1 \%$ and the histological diagnosis. I.G.E. 2010

\begin{tabular}{lll}
\hline $\begin{array}{l}\text { Chromoendoscopic } \\
\text { diagnosis }\end{array}$ & Histological diagnosis & Total \\
\hline & $\begin{array}{ll}\text { Presence of } & \text { Absence of } \\
\text { H. pylori } & \text { H. pylori }\end{array}$ \\
\end{tabular}

\begin{tabular}{|c|c|c|c|}
\hline \multicolumn{4}{|l|}{ Red phenol at $0.1 \%$. } \\
\hline Red phenol at $0.1 \%$. & & & \\
\hline Negative reaction & 40 & 37 & 77 \\
\hline Total & 146 & 49 & 195 \\
\hline
\end{tabular}

\begin{tabular}{lll}
\hline & & C.I. 95\% \\
\hline Sensibility & $72.6 \%$ & 64.9 to $79.2 \%$ \\
Specificity & $75.5 \%$ & 61.9 to $85.4 \%$ \\
Positive predictive value & $89.8 \%$ & 83.1 to $94.1 \%$ \\
Negative predictive value & $48.1 \%$ & 37.3 to $59.0 \%$ \\
Proportion of false positives & $24.5 \%$ & 14.6 to $38.1 \%$ \\
Proportion of false negatives & $27.4 \%$ & 20.8 to $35.1 \%$ \\
Exactitude & $73.3 \%$ & 66.7 to $79.0 \%$ \\
Diagnostic odds ratio & 8.17 & 3.88 to 17.23 \\
J Youden ratio & 0.5 & \\
pre-test probability (prevalence) & $74.9 \%$ & \\
\hline
\end{tabular}

Source: database.

of 8.17 C.I. $95 \%$ ( 3.88 to 17.23 ). The J Youden ratio in our study, was 0.5 which the closer it is to 1 , the higher the quality of the results obtained. Finally the Kappa coefficient (Table II) was of 0.40 C.I. $95 \%$ ( 0.27 to 0.54$)$.

\section{DISCUSSION}

Helicobacter pylori is a bacteria that infects the gastric mucosa in more than $50 \%$ of the world population and it has been recognized as the most important etiologic factor for the development of diverse gastric affections like gastritis, gastroduodenal ulcer, gastric cancer and lymphoma (MALT). Because of the pathogenic potential of these bacteria, it has become necessary to count with efficient methods for its detection (11-13).

H. pylori infection is widely disseminated and its prevalence worldwide is 30.0 to $50.0 \%$ with variations all over the planet which in great measure depends on the global standard of living in each region. In developed countries, infection by this agent is infrequent in children but it increases gradually with age, in developing countries, most of its inhabitants are infected independent of age, these levels of infection reaching close to $70 \%(14,15)$.
Table II. Kappa coefficient

$\begin{array}{ll}0,73 & \text { Total proportion of concordance observed } \\ 0,55 & \text { Expected proportion by random }\end{array}$

C.I. $95 \%$

\begin{tabular}{lll}
\hline Índice Kappa & 0,40 & 0,27 to 0,54 \\
\hline
\end{tabular}

Source: database.

Two studies carried out in Cuba at the Institute of Gastroenterology and "Faustino Perez" Hospital in Matanzas with series of more than 200 patients reported a prevalence of $H$. pylori infection of 80 and $78 \%$ respectively $(16,17)$.

Results obtained during our study correspond with what is reported in the literature, $75 \%$ of patients evaluated had a histological confirmation of $H$. pylori infection.

Patients older than 60 years have a higher frequency of chronic atrophic gastritis and intestinal metaplasia; therefore the density of $H$. pylori decreases significantly $(15,18,19)$.

In 2009 of a total of 2,783 upper digestive tract endoscopies done at the Institute of Gastroenterology in Cuba, 810 corresponded to patients older than 60 years, although this predominance, in our investigation the highest proportion of positive histological test for $H$. pylori were in the range between 41 to 50 years.

It has been described that $H$. pylori infection is cosmopolitan and affects both sexes equally. Gonzalez-Carvajal and other investigators express that sex doesn't seem to be an important question in the prevalence of infection in our country $(16,17,20)$.

At the end of our study, we observed predominance in the female sex, however we consider that this difference is due to the casuistic way of selecting patients and because the female sex come more often to the endoscopy department. In the year 2009 of a total of 2,783 upper digestive tract endoscopies done, 1,571 were on females (56.4\%).

The chromoendoscopy techniques are alternatives to reduce diagnostic errors according to the Japanese society in its recent revision and consensus (2009-2010), levels of sensibility and specificity were established for the different diagnostic methods of $H$. pylori infection, which should be applied by the endoscopic services in an individualized way according to the socio-economic conditions and most frequent pathologies $(21,22)$.

The rapid urease test has good sensibility and specificity, 83 to $74.3 \%$ respectively. Other authors, like Malfertheiner and collaborators or in the Maastrischt III (2007) consensus, report superior results which places it closer to the gold standard which is the histological study in any of its variants (sensibility of $90-93 \%$ and specificity of $95-99 \%)(23,24)$.

Due to its simplicity, low cost and its fast, the urease test is considered the technique of election for the initial diagnosis of $H$. pylori infection in those patients that have an endoscopy done (25). 
The cost of applying red phenol over the gastric mucosa does not differ from that of the urease test and has as advantage that it allows the survey of the mucosa so as to direct the taking of samples, it avoids false positives and/or negatives related with the contamination due to manipulation of samples, temperature, conservation and reading of the same (26-29).

The sensibility, specificity and exactitude in diagnosis with red phenol at $0.1 \%$ in our medium was over $70.0 \%$, this allows us to affirm that this method is useful in the detection of $H$. pylori infection of the gastric mucosa. When calculating the diagnostic odds ratio, the utility of the test was shown. Patients with false negative results had a low density of $H$. pylori infection of the gastric mucosa and on the endoscopic findings, eritematose-erosive gastritis predominated. Most patients with gastroduodenal ulcer or erosive duodenitis were positive to red phenol dye, corroborated with histological study.

The J Youden ratio had an intermediate value and when evaluating the grade of concordance between the two diagnostic tests (Kappa coefficient), in our investigation the test had a moderate value in the diagnosis of $H$. pylori infection. Because there was only one observer, the grade of interobserver concordance could not be evaluated, but we consider that it is not a difficulty in the validation test because only the change of color from yellow to red was evaluated which is not confusing and simple to analyze.

In a study done by Dr. Juan Manuel Ahumada and collaborators in Mexico with 160 patients, they correlated the coloring with red phenol and histology obtaining values of sensibility $91.0 \%$, specificity of $89.0 \%$ and Kappa coefficient of 0.73. Cho and collaborators in Korea report similar results (sensibility 95\%, specificity 93\% and Kappa coefficient 0.80 ), in this investigation they correlated red phenol with breath test with $C^{13}$, including 200 patients. Lastly a Japanese study carried out by Mitsuhashi and Mitomi, correlating the dye with red phenol and culture with the variation of using it in patients with gastric surgery (178 patients), the sensibility and specificity was of $81.0 \%$ and $79.0 \%$ respectively with a Kappa coefficient of $0.59(10,30)$.

In our investigation, staining with red phenol at $0.1 \%$ resulted in a useful method in the diagnosis of $H$. pylori infection of the gastric mucosa and can be applied in our environment, also counting with multiple advantages (topographic location, it avoids contamination, fast and immediate reading, etc.), and can be used in patients with contraindications for the taking of biopsy samples (coagulation disorders).

\section{REFERENCES}

1. Gisbert JP, Calvet X, Gomollón F, Sainz R y Grupo de la Conferencia Española de Consenso sobre Helicobacter pylori. Tratamiento erradicador de Helicobacter pylori. Recomendaciones de la Conferencia Española de Consenso. Med Clin (Barcelona) 2000;114:185-95.

2. Marín R, Gil MV, Castellano MM, Álvarez C, Belda O. Revisión de la aplicación clínica de los colorantes en cromoendoscopía digestiva y su formulación magistral. Farm Hosp 2006;2:112-9.

3. Tanimoto MA. Cromoendoscopía y HP. Rev Gastroenterol Mex 2006;71(3):142-5.
4. Tanimoto MA. Cromoendoscopía en las mucosas del esófago, estómago, y colon. Gastroenterología 2006;7:161-4.

5. Fujita R, Tanimoto MA. Cromoendoscopía. Gastroenterología y Hepatología 2005:250-8.

6. Cittelly DM, Henao SC, Orozco O, Martínez JD. Detección de Helicobacter pylori en Colombia: diferentes metodologías aplicadas a su estudio en una población de alto riesgo de cáncer gástrico. Rev Gastroent 2007;42.No. Especial.

7. Hernández Garcés HR. Manual de endoscopia digestiva superior diagnóstica. La Habana: Editorial Ciencias Médicas; 2008. p. 212-4.

8. Oliveros WR. Cromoendoscopía. Guía de manejo. Revista de Gastroenterología. Asociación Colombiana de Endoscopía Digestiva 2006; 2:23-42.

9. Lee A, Arellano L, Vigneaux J. Revisión de la aplicación clínica de los colorantes en cromoendoscopía digestiva y su formulación magistral. Ficha de datos de seguridad según reglamento 2006;30:112-9.

10. Cho YS, Chae HS, Jang SN, Kim JS, Son HS, Kim HK, et al. Comparison of the (13) C-urea breath test and the endoscopic phenol red mucosal $\mathrm{pH}$ test in the quantification of Helicobacter pylori infection loading. Korean J Intern Med 2008; 23(3):134-9.

11. Roblejo Y, Samada M, Cansino J, Alfonso C, Martínez M, Marrero A. Comparación de métodos diagnósticos de la infección por Helicobacter pylori en pacientes con desórdenes gastroduodenales. Rev Cienc Biol 2005;36:191-7.

12. Torres L.E, Bermúdez L, Roblejo Y, Moreno A, Samada M, Cansino $\mathrm{J}$, et al. Desarrollo de un método serológico propio para el diagnóstico de la infección por Helicobacter pylori y su comparación con dos juegos comerciales. Rev Cienc Biol 2008;39:100-6.

13. Suerbaum S, Michetti P. Helicobacter pylori infection. N Engl J Med 2002;10;347(15):1175-86.

14. Shaw D, Blair V, Framp A, Harawira P, McLeod M, Guilford P, et al. Chromoendoscopic surveillance in hereditary diffuse gastric cancer: an alternative to prophylactic gastrectom? Gut 2005;54:461-8.

15. Carroll R.E. Colon preparation for magnification endoscopy: a rapid novel approach. Endoscopy 2004;36:609-11.

16. González-Carbajal PM. Aspectos epidemiológicos de mayor relieve de la infección por Helicobacter pylori. En: González-Carbajal M, editor. Helicobacter pylori ¿El tercer dogma? Madrid: Autores Productores Asociados; 2003. p. 83-112.

17. Amorés Carraté J, Arredondo Bruce A, Martínez Hiriart B, Estrada Nápoles Y, Pereira Corzo L, Potente Hernández A. Correlación histológica-microbiológica en el diagnóstico de Helicobacter pylori. Rev Mex Patol Clin 2010;3:135-42.

18. Sobrino Cossío S, Hernández Guerrero A, Alonso Lárraga JO, Herrera Goepfert R, Martínez Gómez R. Densidad bacteriana (Helicobacter pylori) y respuesta inflamatoria del cardias, cuerpo y antro gástricos en pacientes con dispepsia. Endoscopia 2007;3:19.

19. Fennerty B. Helicobacter pylori: Why it still matters in 2005. Clev Clin J Med 2005;72:S1-S8.

20. Mitsuhashi J, Mitomi H, Koizumi W, Kikuchi S, Okayasu I, Saigenji K. Spraying of phenol red dye as a screening test for Helicobacter pylori infection in surgically resected stomach specimens. J Gastroenterol 2003;38:1049-52.

21. Gologan A, Graham DY, Sepulveda AR. Molecular markers in Helicobacter pylori-associated gastric carcinogenesis. Clin Lab Med 2005;25:197-222.

22. Vakil N. How to test fot Hp in 2005. Clev Clin J Med 2005;72:S8-13.

23. Malfertheiner P, Megraud F, O'Morain C, Bazzoli F, El-Omar E, Graham D, et al. Current concepts in the management of Helicobacter pylori infection: the Maastricht III Consensus Report. Gut 2007;56:77281.

24. Asaka M, Kato M, Takahashi S, Fukuda Y, Sugiyama T, Ota H, et al. Guidelines for the Management of Helicobacter pylori Infection in Japan: 2009.Revised Edition. Helicobacter 2010;5:1-20.

25. Martín de Argila C, Boixeda D. Consideraciones prácticas en el diagnóstico de la infección por H. pylori. Med Clin (Barc) 2001;117:38691.

26. Gatta L, Ricci C, Tampieri A, Vaira D. Non-invasive techniques for the diagnosis of Helicobacter pylori infection. Clin Microb Infect 2003;9:489-96

27. Megraud F, Lehours P. Helicobacter pylori detection and antimicrobial susceptibility testing. Rev Clin Microb 2007;20:280-322. 
28. Brooks HJ, Ahmed D, McConnell MA, Barbezat GO. Diagnosis of Helicobacter pylori infection by polymerase chain reaction: is it worth it? Diagn Microbiol Infect Dis 200;450:1-5.

29. Torres J, Carnolinga M, Pérez-Pérez G, González G, Muñoz O. Validation or string test for the recovery of Helicobacter pylori from gastric secretion and correlation of its results with urea breath test results, serology, and gastric pH levels. J Clin Microbiol 2001;39(4): 1650-1.

30. Ahumada Trujillo JM, Martínez Carrillo MO, Cruz Parada MC, Gómez Peña Alfaro NS, Gutiérrez AR, Rodríguez Benítez, et al. Utilidad del rojo fenol en la detección endoscópica del Helicobacter pylori. Endoscopia 2007;19(1):112-13 